\title{
Internal Displacement Reactions in Multicomponent Oxides: Part I. Line Compounds with Narrow Homogeneity Range
}

\author{
S.N.S. REDDY, D.N. LEONARD, L.B. WIGGINS, and K.T. JACOB
}

As a model of an internal displacement reaction involving a ternary oxide "line" compound, the following reaction was studied at $1273 \mathrm{~K}$ as a function of time, $t$ :

$$
\mathrm{Fe}+\mathrm{NiTiO}_{3}=\text { "Ni" + "FeTiO } "
$$

Both polycrystalline and single-crystal materials were used as the starting $\mathrm{NiTiO}_{3}$ oxide. During the reaction, the $\mathrm{Ni}$ in the oxide compound is displaced by $\mathrm{Fe}$ and it precipitates as a $\gamma-(\mathrm{Ni}-\mathrm{Fe})$ alloy. The reaction preserves the starting ilmenite structure. The product oxide has a constant Ti concentration across the reaction zone, with variation in the concentration of $\mathrm{Fe}$ and $\mathrm{Ni}$, consistent with ilmenite composition. In the case of single-crystal $\mathrm{NiTiO}_{3}$ as the starting oxide, the $\gamma$ alloy has a "layered" structure and the layer separation is suggestive of Liesegang-type precipitation. In the case of polycrystalline $\mathrm{NiTiO}_{3}$ as the starting oxide, the alloy precipitates mainly along grain boundaries, with some particles inside the grains. A concentration gradient exists in the alloy across the reaction zone and the composition is $>95$ at. pct $\mathrm{Ni}$ at the reaction front. The parabolic rate constant for the reaction is $k_{p}=1.3 \times 10^{-12} \mathrm{~m}^{2} \mathrm{~s}^{-1}$ and is nearly the same for both single-crystal and polycrystalline oxides.

\section{INTRODUCTION}

A displacement reaction between a metal and an oxide involves the reduction of a noble oxide by a reactive metal. Previous studies of solid-state displacement reactions between metals and oxides ${ }^{[1-6]}$ have identified several types of reaction morphologies and their relationship to the thermodynamic and diffusional transport properties of product phases. Some of the reaction couples considered were $\mathrm{Cu}_{2} \mathrm{O} / \mathrm{Co}^{[1]}$ $\mathrm{Cu}_{2} \mathrm{O} / \mathrm{Ni}^{[1]} \mathrm{Cu}_{2} \mathrm{O} / \mathrm{Fe},{ }^{[1,2]} \mathrm{Cu}_{2} \mathrm{O} / \mathrm{Co}_{1-x} \mathrm{Fe}_{x},{ }^{[3]} \mathrm{NiO} / \mathrm{Fe} e^{[1,4]}$ $\mathrm{NiO} / \mathrm{Al},{ }^{\left[{ }^{[}\right]}$and $\mathrm{NiO} / \mathrm{Mg} .{ }^{[6]}$ In particular, Rapp et al.${ }^{[1]}$ have considered the reactive interface stability as a function of the diffusional rate control in the product phases. Internal reactions occur inside a metal or ceramic matrix; an example is the well-known internal oxidation of alloys. ${ }^{[7]}$ Schmalzried ${ }^{[8,9]}$ has considered internal oxidation and reduction reactions in multicomponent oxides and an extensive review is given by Schmalzried and Backhaus-Ricoult. ${ }^{[10]}$ Shook et al. ${ }^{[11]}$ have considered the internal displacement reaction in a metal matrix by studying the reaction between $\mathrm{Cr}$ and $\mathrm{MoO}_{2}$ inside a Ni matrix. As part of a study of the internal displacement reactions in multicomponent oxides, the reaction between a metal and ternary oxide compound of a narrow homogeneity range (a line compound) is considered in this article, along with the results for a model reaction between $\mathrm{Fe}$ and $\mathrm{NiTiO}_{3}$ at $1273 \mathrm{~K}$. Reactions involving solid solutions of oxide compounds will be considered in Part II of this series of articles. ${ }^{[12]}$ These reactions can

S.N.S. REDDY, Senior Engineer and L.B. WIGGINS, Senior Technical Staff Member, are with the Systems and Technology Group, IBM Corporation, Hopewell Junction, NY 12533. Contact e-mail: snreddy@us.ibm.com D.N. LEONARD, Graduate Student, is with the Department of Materials Science, North Carolina State University, Raleigh, NC 27695. K.T. JACOB, Professor, is with the Department of Metallurgy, Indian Institute of Science, Bangalore560012 , India.

Manuscript submitted July 13, 2004 be exploited to manufacture metal-ceramic composites having unique physical and mechanical properties.

\section{DISPLACEMENT REACTIONS INSIDE A LINE COMPOUND}

An internal displacement reaction in an oxide compound of a narrow homogeneity range is defined by the following chemical reaction:

$$
\begin{array}{r}
\mathbf{A}(\text { metal })+\mathbf{B C O}_{m+n}(\text { oxide })=" \mathbf{B} "(\text { metal })+“ \mathbf{A C O}_{m+n} " \\
\text { (oxide) } ; \Delta G_{1}<0
\end{array}
$$

where $\Delta G_{1}$ is the Gibbs energy change for the reaction. In Reaction [1], cation $\mathbf{B}$ is displaced by cation $\mathbf{A}$ in the oxide, without changing the crystal structure of the oxide, and cation C does not participate in the chemical exchange reaction. During the reaction, "B" is typically precipitated as A-B alloy and the product oxide, "ACCO $\mathbf{C}_{m+n}$ ", is usually $(\mathbf{A}, \mathbf{B}) \mathbf{C O} \mathbf{O}_{m+n}$. The reaction is associated with a volume increase in the product zone, mainly due to the volume of "B" precipitate. The oxide systems in which Reaction [1] is possible are illustrated in Figure 1 and discussed in the following.

Consider three binary oxides, $\mathbf{A O}_{m}, \mathbf{B O}_{m}$, and $\mathbf{C O}_{n} ; \mathbf{A O}_{m}$ and $\mathbf{B O} \mathbf{O}_{m}$ have the same crystal structure (different from that of $\mathbf{C O}_{n}$ ) and form a continuous series of solid solutions. Also, the thermodynamic stability of the binary oxides is such that $\Delta G^{\mathrm{o}}\left(\mathbf{C} \mathbf{O}_{n}\right)<<\Delta G^{\mathrm{o}}\left(\mathbf{A} \mathbf{O}_{m}\right)<\Delta G^{\mathrm{o}}\left(\mathbf{B O}_{m}\right)$. The binary oxides combine to form ternary line compounds of narrow homogeneity range, e.g., $\mathbf{A C O} \mathbf{C O}_{m+n}$ and $\mathbf{B C O} \mathbf{O}_{m+n}$, and having the same crystal structure. The meaning of line compound is that the ratio $\mathbf{A}: \mathbf{C}$ or $\mathbf{B}: \mathbf{C}$ has a constant value (equal to $1: 1)^{*}$ and any deviation from it will result in the

*Other ternary line compounds, such as $(\mathbf{A} \text { or } \mathbf{B})_{2} \mathbf{C O}_{2 m+n}$ or $(\mathbf{A}$ or B) $\mathbf{C}_{2} \mathbf{O}_{m+2 n}$, referred to as (2:1) or (1:2), respectively, are not considered for the sake of simplicity. However, reactions in these compounds follow the same technical arguments that are applied to (1:1) compounds. 